\title{
The Impact of Stadium Announcements on Residential Property Values: Evidence from a Natural Experiment in Dallas-Fort Worth
}

\author{
Carolyn A. Dehring ${ }^{\dagger}$, Craig A. Depken ${ }^{\dagger \dagger}$, and Michael R. Ward ${ }^{\dagger \dagger}$
}

September 2006

\begin{abstract}
We investigate the impact of a potential new sports venue on residential property values, focusing on the National Football League's Dallas Cowboys' search for a new host city in the Dallas-Fort Worth area. We find that residential property values in the city of Dallas increased following the announcement of a possible new stadium in the city of Dallas. At the same time, property values fell throughout the rest of Dallas County, which would have paid for the proposed stadium. These patterns reversed when the Dallas stadium proposal was abandoned. Subsequently, a series of announcements regarding a new publicly-subsidized stadium in nearby Arlington, Texas, had a deleterious effect on residential property values in Arlington. In aggregate, average property values declined approximately 1.5\% relative to the surrounding area before stadium construction commenced. This decline was almost equal to the anticipated household sales tax burden, suggesting that the average expected amenity effect of hosting the Cowboys in Arlington was not significantly different from zero.
\end{abstract}

JEL Classification Codes: L83, R53, H73

Keywords: economic impact, event studies, sports, property values, stadiums

${ }^{\dagger}$ Carolyn A. Dehring, Department of Insurance, Legal Studies and Real Estate, The University of Georgia, 706-542-3809 (office), cdehring@terry.uga.edu

${ }^{\dagger \dagger}$ Craig A. Depken, II, Department of Economics, University of Texas at Arlington, 817272-3290 (office), 817-272-3145 (fax), depken@uta.edu

${ }^{\dagger+}$ Michael R. Ward, Department of Economics, University of Texas at Arlington, 817272-3090 (office), 817-272-3145 (fax), mikeward@uta.edu 


\section{Introduction}

Public expenditures on a project, and the requisite public taxation, may be economically justified if the benefits from the project outweigh the costs. Most public projects, such as parks, roads, and police, have public good or external benefits that are difficult to quantify making the evaluation of individual projects difficult. Eventually, however, the net benefits of the accumulated projects are represented in the cost of admission to the community in the form of housing prices or rents. Positive net benefit projects raise house prices in aggregate while negative net benefit projects lower house prices in aggregate. We measure the net benefits from the public consideration of a large discrete project, a professional sports stadium funded by a local sales tax increase.

The public expenditure on sports stadiums has long been controversial, and there is an extensive empirical literature investigating the impacts of new stadiums on local economies. The overwhelming majority of studies find little or no net impact from either a new stadium or from hosting a professional sports franchise (see Siegfried and Zimbalist (2000) and Rappaport and Wilkerson (2001) for thorough reviews). These empirical results contradict the nominal political justifications offered by potential host cities for providing public subsidies for professional sports venues: that a new stadium will provide the catalyst for an improvement in the community's attributes. Nevertheless, new stadiums continue to be built on a regular basis, many of which are approved by local referenda. ${ }^{1}$

We contribute to a small but growing literature focusing on the impact of professional sports venues on residential property values. Specifically, we investigate two sets of stadium announcements concerning the National Football League's Dallas Cowboys' search for a host-city in the Dallas-Fort Worth Metroplex. These announcements provide a quasi-natural experiment to test whether the announcement that a stadium might be built in a particular area has any immediate impact on the sale prices of residential properties. Because a stadium is costly to relocate, we treat the announcements of potential stadium relocation as changing the probability of a large

\footnotetext{
${ }^{1}$ During the 1990s and through the early 2000 s, cities across the United States have engaged in what could be termed a venue building spree. A little over $50 \%$ of the 122 teams in the four major professional leagues in the US have moved into a new or substantially renovated venue since 1990. In aggregate, these new venues cost an estimated $\$ 13.45$ billion in current ( $\$ 16$ billion in 2005 CPI adjusted) dollars. Public dollars have contributed $\$ 10.27$ billion, or two-thirds, to the construction and maintenance of new sports venues.
} 
discrete event and test for accumulated and differential impacts of stadium announcements on contemporaneous residential property values.

We find that property values increased in the city of Dallas after the announcement that the Cowboys might move to a new stadium built to replace the Cotton Bowl. However, in Dallas County, which would have paid for the stadium with new taxes, residential property values decreased after the announcement of the Fair Park stadium proposal. Consistent with these results, when the Fair Park stadium proposal was abandoned, properties in the city of Dallas declined in value while the property values in Dallas County rebounded. In the end, the accumulated net effect of the stadium announcements for both Dallas City and Dallas County was zero, consistent with a return to the status quo ante. When analyzing three announcements concerning a potential new stadium in Arlington, we find that the accumulated impacts of the stadium announcements reflected between a 1.3 and 1.5 percent reduction in residential property sales prices in Arlington, ceteris paribus. In other words, at each point in which it became more certain that Arlington would contribute local tax dollars to a new stadium for the Cowboys, property values in Arlington fell. While the reduction in property values reflects the combination of an expected amenity effect and an expected tax effect, we cannot reject the null hypothesis that the expected amenity effect was equal to zero before stadium constructed commenced.

\section{A New Dallas Cowboys Stadium: Where and When?}

In April, 2001, the Dallas Cowboys announced they were interested in obtaining a new publicly subsidized stadium to replace the aging Texas Stadium. Built in 1972, Texas Stadium lacks many of the modern revenue generating aspects of new stadiums, particularly modern luxury suites and a closed or retractable roof. During the Spring and Summer of 2001, team owner Jerry Jones entertained initial proposals from a number of cities in the Dallas-Fort Worth Metroplex, including current-home Irving, Grapevine, Arlington, Grand Prairie, and Dallas. These preliminary discussions were tabled after the September 11, 2001 attacks in New York City and did not come back to public light until late 2003.

At that time, the Cowboys once again publicly mentioned their desire for a new stadium and 
suggested that the stadium could be built in Irving, near Texas Stadium. The response to this proposal by the city of Irving was not encouraging. Because of Irving's relatively small tax base (population 130,000 in 2000) and its inability to raise the sales tax rate beyond the state mandated cap, the city of Irving alone was unlikely to be able to finance its contribution to the anticipated $\$ 1$ billion project. $^{2}$ This, in turn, caused the Cowboys to look outside of Irving for a new home.

In the early months of 2004 , a number of cities indicated their desire to contend for the new stadium but it was equally apparent that these cities suffered the same problems as Irving - too small of a tax base and/or little room under the state sales tax limit. In March of 2004, it was suggested that Fair Park in downtown Dallas, home of the 72 year old Cotton Bowl, could be possible site for a new Cowboys stadium. The possibility that the Cotton Bowl would be replaced by a new retractable roof stadium generated considerable excitement in the Dallas community. A new stadium in Fair Park would move the Dallas Cowboys back to their original home town (rather than playing in a suburb of Dallas) and would ensure both the annual University of Texas-University of Oklahoma football game and the annual Cotton Bowl would remain in Dallas. Moreover, a new stadium would allow Dallas to contend to host any number of events, including a BCS Championship football game, a Super Bowl, or an NCAA Final Four. Fair Park also has the advantage of an existing infrastructure able to handle large events. ${ }^{3}$

The Fair Park proposal called for the County of Dallas to increase its sales tax rate by one half of one percent to pay for the stadium. A county-wide sales tax increase was proposed to expand the tax base enough to cover the anticipated construction costs. However, notwithstanding the excitement generated by the stadium proposal, one major problem became apparent. The City of Dallas was contractually obligated to retire the public debt it incurred to build the $\$ 410$ million American Airlines Arena (home of the National Hockey League's Dallas Stars and the National Basketball Association's Dallas Mavericks) before spending any additional tax dollars on a new professional sports venue of any kind. This contractual obligation removed the city of Dallas, but

\footnotetext{
${ }^{2}$ The State of Texas has no state income tax. The state levies a $6.25 \%$ sales tax to fund the state government. Cities are allowed to add up to an additional $2 \%$ sales tax to fund local government and special projects such as road maintenance and stadiums. As of 2004, the city of Irving had a $1 \%$ sales tax for local government and a $1 \%$ sales tax to contribute to the Dallas Metro Transit system. Therefore, the city of Irving had no room under the existing state mandated sales tax cap of $8.25 \%$.

${ }^{3}$ Fair Park is home of the annual Texas State Fair, the largest state fair in the country.
} 
not the rest of Dallas County, from the tax jurisdiction for a new football stadium. ${ }^{4}$ When it became clear that the city of Dallas would not be contributing any tax proceeds towards a new stadium, the remaining Dallas County population and city officials cooled to the idea of building a new stadium in Fair Park. The Fair Park proposal was officially abandoned in the public media on June 6, 2004. Thereafter, the Dallas Cowboys publicly renewed their search for a new host city.

On July 17, 2004, the mayor of Arlington announced that he had been in negotiations with the team about the potential of building a new stadium in Arlington. In many ways Arlington is also a good place to locate a new stadium. Arlington is located between Fort Worth and Dallas, has access to multiple interstates and highways, and the city already hosts the Texas Rangers Major League Baseball club and a Six Flags amusement park. Arlington is also the third largest city in the Dallas-Fort Worth Metroplex (after Fort Worth and Dallas), and it's approximate $\$ 4$ billion annual economy and 360,000 people provide a sufficiently large tax base from which stadium subsidies can be extracted. Arlington built the Rangers baseball stadium in 1994, following a public referendum in 1991, and the city paid off the last of the baseball stadium bonds in early 2001. Afterwards, in accordance with state law, the city of Arlington reduced it's local sales tax rate by one half of one percent. Therefore, in early 2004, the city of Arlington was unique among area cities in that it had a large tax base and room under the state-mandated sales tax cap. ${ }^{5}$

On August 17, 2004, the Arlington city council approved a ballot initiative to be decided during the November 3, 2004 general election. The ballot initiative was announced to include two elements. The first would approve up to $\$ 325$ million in public money to contribute to land acquisition and construction costs for a new retractable roof football stadium for the Dallas Cowboys. The second part authorized the city to increase the local sales tax by a half cent, increase local hotel taxes by two percentage points, and increase Arlington-based car rental taxes by five percentage points to finance the city's contribution to the stadium. The ballot initiative was approved by the voters of Arlington on November 3, 2004 with 55\% voting in favor and 45\% voting against. The precise stadium location was determined in early 2005, and in April 2005 the city of Arlington began

\footnotetext{
${ }^{4}$ The City of Dallas passed the referendum to build a new basketball/hockey arena in 1998 and does not anticipate retiring the debt for that stadium until well after 2020 .

${ }^{5}$ At the time the stadium proposal was announced, the prevailing local sales tax rate in Arlington was $7.5 \%$.
} 
collecting the additional taxes. The new stadium is scheduled to open for the 2009 football season.

During the stadium campaign, the pro-stadium activists solicited an economic impact study, and produced television, radio, mass mailings, and newspaper advertising that touted the economic impact figures generated in their study. Ultimately they out-spent anti-subsidy activists $\$ 6$ million to $\$ 43,000$. The Cowboys were large contributors to the pro-stadium proponents, had players post yard signs, and the famous team cheerleaders attended campaign events to encourage passage. ${ }^{6}$ Proponents claimed that the new stadium would bolster Arlington's entertainment-focused industry and that the new stadium would make it more attractive for people to live in the area in and around the two-stadium complex. This in turn, led some to claim that the new stadium would not only contribute to the quality of life in the city of Arlington but would also cause an increase in property values.

\section{The Potential Impacts of a New Stadium on Property Values}

Land use externalities are costs or benefits generated by land uses which flow outside of market transactions. Because externalities have been shown to be capitalized into house prices, they provide the justification for municipal zoning. In the absence of zoning, the market will over-allocate land to negative externality-producing "lower" uses. Externalities can influence prices in two ways: scale effects and boundary effects. Scale effects relate to the absolute amount of the externality-producing use, while boundary effects relate to the proximity to the externality-producing use. ${ }^{7}$

Two papers have investigated the impact of a professional sports franchise or sports venue on house prices. Carlino and Coulson (2004) discuss the public good facet of professional sports teams, what they term nonexcludable beneficiaries. The perceived benefits that might accrue to those who will never attend a game relate to an enhanced sense of "civic pride," which should

\footnotetext{
${ }^{6}$ This rent-seeking behavior is consistent with Depken (2006) who finds that much of the public cost of a new professional baseball stadium is capitalized in the value of the franchise.

${ }^{7}$ There is a large literature investigating land-use externalities. A small sample includes estimating the effect of water amenities on house prices [Knetsch (1964), Lansford and Jones (1995) Darling (1973), Brown and Pollakowski (1977), Cassel and Mendelson (1985)], the effect of public open space externalities on house prices [Correll et al (1978), Dehring and Dunse (2006), Epsey and Owusu-Edusei (2001), Irwin (2002), and Weicher and Zerbst (1973)]. The effects of potentially negative externalities such as transmission towers, power lines, group homes, airports, and landfills on residential property values have also been examined.
} 
cause an increased willingness to pay for local housing, among other things. In their examination of monthly rents in 60 metropolitan statistical areas (MSAs) in 1993 and 1999, Carlino and Coulson find rental premiums in both the central business district (CBD) and the surrounding suburbs of cities that host NFL franchises. ${ }^{8}$

$\mathrm{Tu}$ (2005) examines the impact of FedEx field, the home of the NFL's Washington Redskins, on surrounding house prices pre- and post- stadium construction in Landover, Maryland. Tu compares prices within three miles of the FedEx field site across three time periods: pre-development, development, and post-development, where the development period starts from when the Landover site was first revealed as a possible site of the stadium. Pre-development, he finds that properties closer to the proposed stadium site had lower value relative to properties located further away from the proposed site. However, this gradient became less pronounced following the stadium's development, suggesting a positive externality was generated by the new stadium for properties located closer to the stadium. Tu estimates an aggregate increase in property values of approximately $\$ 42$ million was generated by the new stadium.

In the case where a new stadium is funded with a local sales tax, any capitalization in local residential property prices identified with the stadium project are the sum of three possible effects: a negative tax effect, a (potentially) positive "civic pride" effect common to the entire city (but not necessarily evenly distributed across the entire population), and an ambiguous externality effect. ${ }^{9}$ Any positive externalities created by a stadium could be discrete or related to proximity, such as ease of access and opportunities for parking revenue. Potential negative externalities would include diminished view, traffic congestion, noise, loss of privacy, and crime. Accordingly, the impact of a new stadium on house values is ambiguous ex ante, and is therefore a question to be resolved empirically.

Our analysis is closest to Tu's but we differ in that we focus on announcements that a stadium might/will be built in a particular area, all of which are pre-development, rather than pre and post stadium construction. We implicitly assume that housing markets exhibit informational efficiency,

\footnotetext{
${ }^{8}$ Coates, Humphreys and Zimbalist (2006) suggest that Carlino and Coulson's estimation results are based on relatively few observations and are therefore not as robust as claimed. In a rejoinder Carlino and Coulson (2006) suggest this argument is incorrect.

${ }^{9}$ See Oates (1969), Bloom Ladd and Yinger (1983), and Man and Bell (1996).
} 
such that any expected net externality effects are capitalized in house prices well in advance of the actual project completion. Our paper also differs from Tu in that we look at the immediate impact of stadium announcements on property values. Tu finds that FedEx field enhanced proximate property values by approximately $\$ 42$ million in aggregate, which reflects a pure amenity effect. In contrast to the Cowboys stadium, FedEx field was essentially privately funded, implying no local tax effect generated by the stadium.

Our use of announcement dates rather than project completion dates is not without precedent. For example, Colwell, Dehring, and Lash (2000) use announcement dates to test the effect of group homes on neighborhood house prices. They measure the announcement date as the day the public was first made aware that a group home was to be opened in the area. Similarly, Dehring (2006) uses ordinance dates, rather than the effective dates of regulation, to investigate the effect of coastal construction code changes on vacant land development in Florida.

\section{Data and Methodology}

Our test of the impact of stadium announcements on residential property values combines hedonic pricing models, event study methodology, and difference-in-difference estimators. Hedonic pricing reveals the implicit price of housing and location attributes, as well as any price effects from the stadium. ${ }^{10}$ Because each announcement increases or decreases the probability that a stadium would be built in a specific location, each is allowed to have an impact on property values (McKinlay, 1997). We employ a difference-in-difference identification strategy to distinguish the net amenity effect before and after each announcement.

There is an existing large literature on hedonic pricing models of houses. These studies typically find that in large metropolitan areas most of the variation in house prices can be explained by a house's age, size, and the quality of local public schools. Other factors include the the availability of parking, whether the property includes a swimming pool, and the time of sale. Following standard practice, we include these controls as well as the variables of interest to measure stadium effects.

\footnotetext{
${ }^{10}$ Rosen (1973) is the ground-breaking hedonic pricing study, but see Sirmans, Macpherson and Zietz (2005) for a thorough review of hedonic pricing in real estate.
} 
We investigate the impact of five separate stadium announcements, two of which concern Dallas, and three of which concern Arlington. The first two announcements represent the stadium potentially coming to, and then leaving, the Fair Park district near downtown Dallas. The first (second) of these announcements is associated with an increased (decreased) probability that a new stadium would be built in downtown Dallas. Three additional announcements center on the proposal to build a stadium in Arlington. These announcements correspond with the dates on which the mayor of Arlington announced his previous negotiations, the city council vote to approve a ballot initiative, and the affirmative ballot initiative outcome, respectively (see Table 1).

One obvious difference from standard event studies is that we cannot track daily changes in the value of a single house but must draw inferences from prices of different houses. Another is that we are not calculating the return relative to the general market as one would do when analyzing abnormal stock returns. Any price effect from a proposed stadium should be reflected in the prices of houses benefiting, or suffering, from the expected net effect at the time of the announcement. For example, the public expense of the Fair Park stadium was to have been funded by taxation within Dallas County. All else equal, we expect this tax effect to cause a reduction in Dallas County house prices after the first announcement and a commensurate increase after the second announcement.

We employ a general difference-in-difference identification strategy to calculate the effects of stadiums. For example, for the first announcement, we include a Dallas County dummy variable, an announcement date dummy variable, and the Dallas County dummy variable interacted with the post-announcement period. Since the measured effect of the interaction represents the differential impact of the stadium on houses in Dallas County relative to either general announcement effects independent of location or Dallas County effects at different times, we identify it with the expected effect of increased taxation to finance the stadium on Dallas County houses.

Our estimating equation is represented as:

$\ln \left(P R I C E_{i}\right)=\beta F E A T U R E S_{i}+\delta A N N O U N C E_{i}+\gamma A N N O U N C E_{i} \times T A X J U R I S_{i}+\epsilon_{i}$,

where $\beta, \delta$, and $\gamma$ are vectors of parameters to be estimated, and $\epsilon_{i}$ is a composite zero-mean error term that facilitates neighborhood fixed effects and spatial correlation. 
The dependent variable $\ln (P R I C E)$ is the logarithm of the sale price of the house. The vector FEATURES includes both structural and location attributes including structure age, aged squared, amount of living area, area squared, the number of baths, the existence of a pool, number of parking places, and dummy variables for the public schools serving the school. The vector ANNOUNCE includes the appropriate dummy variables, for the sample analyzed, indicating whether the sales price was agreed upon after each of the five announcements. The variable $T A X J U R I S$ is a dummy variable indicating that the home is within the jurisdiction of the proposed tax intended to fund the public share of the stadium building expense.

For the Dallas Fair Park proposal, we include two separate dummy variables, one for the city of Dallas and one for all the other cities in Dallas County. The initial Fair Park stadium proposal included a county-wide sales tax to pay for the stadium. However, the city of Dallas likely would not have contributed to the football stadium until it had retired its debt for the basketball-hockey arena built in 1998. It is not clear if homeowners in the city of Dallas anticipated higher taxes or not. If the market anticipated tax burdens correctly, the announcement of the stadium coming to Dallas would have been a pure amenity effect in the city of Dallas, similar to the effect found by $\mathrm{Tu}$ (2005), while property value changes in the rest of Dallas County would have been a net effect. When the Fair Park stadium proposal was abandoned, the reverse pattern would be expected.

For the Arlington stadium proposal, we define TAXJURIS as the city of Arlington. We identify each announcement in Arlington as signalling an increased likelihood that a stadium would be built in Arlington. Thus, if the proposed stadium had a net positive (negative) expected impact on the community's attributes, we anticipate each announcement to correspond with an increase (decrease) on house prices in Arlington, relative to the surrounding areas.

Three points regarding the tax jurisdiction indicators are worth mentioning. First, for both stadium proposals, the public contribution to the stadium's cost was to be financed by an increase in the local sales tax rate. Citizens of one city or county may well be taxed in proportion to their taxable purchases within the jurisdiction. However, some owners of houses in the tax jurisdiction may purchase taxable items outside the jurisdiction. The converse is true for homeowners in nearby cities. Because the land area of Dallas City, Dallas County, and Arlington are large relative 
to normal shopping distances, we expect the measurement error from these border regions to be small. Second, by using a dummy variable, we are implicitly assuming that the tax burden is roughly proportional to the house value. This is likely to hold since both housing value and expenditures on taxable items are likely to be highly correlated with household income. Third, there may be a positive amenity effect from having one's town associated with the team regardless of the distance to the stadium. In this case, the measurement of the tax jurisdiction effect is the net of the tax and amenity effects.

We employ a Generalized Least Squares (GLS) estimator that takes into account possible heteroscedasticity and spatial autocorrelation. Since we cannot reject that the error term has a common component at the city level, our estimator allows the variances to differ across geographic areas. We include a fixed-effect for the public elementary-school that a homeowner's children would likely attend. The elementary school almost always identifies a middle and a high school as well. ${ }^{11}$ However, it is likely that there is also spatial correlation that influences the variance of house properties as well. We therefore use a robust GLS estimator that allows for fixed effects (mean-shifters) and clustering (variance shifters) based on elementary-schools. The estimator we employ uses a great deal of information as there are 745 elementary schools included in the Dallas-centered sample, and 649 elementary schools included in the Arlington-centered sample.

Our data include two samples of residential property sales in the Dallas-Fort Worth Metroplex from January 2004 through March 2005. The residential property sales data were collected from the Multiple Listing Service. We subtract thirty days from the closing date, reported by the MLS, to more closely align house contract dates with the announcement effects. ${ }^{12}$ To avoid undue influence of outlier properties, we excluded observations that corresponded to houses older than 70 years old, more than 7,000 square feet, less than 500 square feet, or more than seven bathrooms. Both the Dallas-centered and Arlington-centered samples were further limited by excluding properties beyond 20 miles from the proposed stadium site. The Dallas-centered sample is ultimately comprised

\footnotetext{
${ }^{11}$ Evidence suggests that there is a high correlation between property value and the quality of the public schools (see Downes and Zabel, 2002).

${ }^{12}$ This is not always guaranteed to directly align house sale dates with announcement dates as closing times can differ. However, the average time to close is approximately 30 days and we anticipate that any other measurement error introduced by our adjustment is not systematically related to the stadium announcements. Therefore, the adjustment would only influence the efficiency, but not the consistency, of our estimation results.
} 
of 42,351 observations; the Arlington-centered sample is comprised of 32,061 observations. The descriptive statistics of the data are provided in Table 2. The first two columns report the mean and standard deviation of our dependent and independent variables for the Dallas-centered sample. The second two columns report the descriptive statistics for the Arlington-centered sample.

\section{Empirical Results and Discussion}

We estimate the difference-in-difference model described in equation (1) including elementary-school fixed effects. We accommodate spatial correlation in property values by clustering the error terms by elementary school. The full estimation results are detailed in Table 3 through Table 5 .

The primary hedonic regression results are provided in Table 3. The left column provides results pertaining to the Dallas sample, centered on the Cotton Bowl in downtown Dallas, whereas the right column provides results pertaining to Arlington, centered on the Ballpark in Arlington (the approximate site of the proposed Cowboys stadium). The hedonic regression results are consistent with the results obtained using data from other large metropolitan areas. For instance, in both the Dallas and Arlington samples, each additional year of age reduces the average property by approximately 1.3 percent, although this decline is tempered a bit by the positive coefficient on the quadratic of age. Likewise, each additional 20 square feet adds approximately 1 percent to the value of the house, although this increase is also tempered by the negative parameter estimate on the quadratic of square footage. In both cities, a pool on the property adds approximately $8.5 \%$, each bathroom adds an additional $5 \%$, each covered parking spot adds $5 \%$, and an additional story reduces the average property value by approximately $9 \%$. As in all hedonic regressions, the parameter estimates are interpreted assuming ceteris paribus.

The primary empirical results of interest, those pertaining to the stadium announcements, are reported in Tables 4 and 5. For the Dallas sample we focus on the first two announcements: the Cowboys might relocate to Fair Park (Announcement 1), and the Cowboys will not relocate to Fair Park (Announcement 2). In this case, the city of Dallas would enjoy the amenity benefits of the stadium but would not have contributed to the stadium subsidy. However, the rest of the County of Dallas would have paid for the stadium without enjoying any proximity amenities associated 
with the stadium. Therefore, for the Dallas sample we control for both Dallas and Dallas County announcement effects. In the case of Arlington, we focus on the last three stadium announcements: the city was in negotiations with the team (Announcement 3), the Arlington city council approved a ballot initiative concerning the stadium (Announcement 4), and the affirmative outcome of the November 2004 ballot initiative (Announcement 5).

The results in Table 4 present an interesting story. The results from the Dallas analysis suggest that the initial announcement that the Cowboys might relocate to Fair Park corresponded with an increase in property values in Dallas City. On the other hand, the estimated impact of the first announcement on property values throughout the rest of Dallas County is negative (although not distinguishable from zero). When the Cowboys announced they were not going to relocate to Fair Park in downtown Dallas, one would expect the exactly opposite qualitative impacts on property values in the city of Dallas and throughout Dallas County. The results in column 1 of Table 4 support this expectation. The second announcement correlates with a reduction in property values in the city of Dallas and an increase in property values throughout the rest of Dallas County (although neither parameter estimate is significant). Combined, these results suggest that there were expectations of amenity effects of a Cowboys stadium but these benefits were outweighed by the expected tax burden of the stadium.

The second column of Table 4 reports similar estimation results for the Arlington sample. In this case, only the last three announcement dates are investigated. Because Arlington was the only city in the metropolitan area that would charge additional sales tax to pay for the public contribution to the stadium, there is no need for a separate county dummy variable. The results suggest that each of the first two stadium announcements concerning Arlington correlated with a reduction in residential property values in Arlington relative to other non-Arlington properties within twenty miles of the proposed stadium site. The last announcement event, corresponding with the affirmative November vote, carries a positive parameter estimate. While none of the three parameter estimates are statistically significant on their own, the $95 \%$ confidence interval of the sum of the three announcement effects is $[-0.028,0.003]$ centered on -0.013 . This provides some evidence that the accumulated impact of the Arlington stadium announcements was negative and 
statistically different from zero $(p=0.08)$. The accumulated impact of the stadium announcements in Arlington is consistent with the impacts of a possible stadium on property values in Dallas County.

One possible problem with the results reported in Table 4 is the assumption that each announcement has a separate and identifiable impact on residential property values. An alternative approach is to restrict each stadium announcement to have an identical incremental effect on residential property values. In this case, there should be no aggregate net effect of the stadium announcements in Dallas or Dallas County as the Cowboys ultimately did not relocate to either of those areas. While the net impact of the stadium announcements in Arlington are ambiguous, the results in Table 4 suggest the net impact was negative.

In column two of Table 5, the results from the Dallas sample suggest no net impact on property values after the stadium proposal for Fair Park was abandoned. ${ }^{13}$ However, in column three of Table 5, the results from the Arlington sample suggest that each of the three announcements corresponded with an average reduction in residential property values in Arlington of approximately one half of one percent. Therefore, the aggregated impact of the stadium proposal for Arlington was an average reduction in Arlington property values of approximately 1.5\%, a result that is statistically different from zero $(p=0.023)$.

\section{Conclusions}

The aggregated impact of stadium announcements when stadiums are funded by municipal tax dollars is the combination of three distinct elements: the tax burden, which causes a reduction in property values, the overall city amenity effect, which causes an increase in property values, and the proximity amenity effect, which has an ambiguous effect on residential property values. The results presented herein suggest that the aggregated expected city amenity effect and local sales tax burden associated with the proposal to build a publicly subsidized stadium for the Dallas Cowboys in Arlington, Texas, reduced residential property values.

What is the magnitude of the amenity effect for Arlington? A back of the envelope calculation

\footnotetext{
${ }^{13}$ We can reject that the increase and subsequent decrease in properties values was zero.
} 
suggests that a household of four with $\$ 50,000$ of income might contribute up to $\$ 60$ per year in local sales tax dedicated to the stadium construction. ${ }^{14}$ Assuming a wage growth rate of $4.5 \%$ per year, the thirty year present value of the tax payments would be approximately $\$ 2000$. During the sample period, the average residential property in the city of Arlington sold for $\$ 120,000$. The $95 \%$ confidence interval for the accumulated deleterious effect of the various stadium announcements on average property values in Arlington is $[-\$ 3343,-\$ 142]$, centered on $-\$ 1,742$. Therefore, the average reduction in property value is not statistically different from the expected additional local sales tax burden. In other words, the general amenity effect in the city of Arlington is not distinguishable from zero.

This result differs from that of $\mathrm{Tu}(2005)$ who found a positive amenity effect for properties located within three miles of the National Football League's Washington Redskins's stadium built in 1995. There may be significant differences between the area of Landover, MD, where the Redskins built their stadium, and Arlington, TX, where the Cowboys are building their stadium. Additionally, the tax effects associated with the Cowboys project did not plague the Redskins project and this might help explain the differences in the results.

Two questions remain unanswered. First, what is the pattern of changes in residential property values in the city of Arlington as the Cowboys stadium is constructed and what will happen to residential property values after the stadium opens? If property values in Arlington increase after the new stadium opens, this might simply offset the reduction in property values incurred when the stadium project was announced. Second, if the property values fell in the city of Arlington during the stadium campaign, why did the stadium project win the approval of a majority of Arlington voters? Perhaps the distribution of the net benefits of a Cowboys stadium were sufficiently distorted such that a majority of the voters approved the measure even as average property values fell. On the other hand, the transient nature of Arlington's population might have caused an information asymmetry about the net effects of public expenditures on stadiums. These questions provide a possible road map for future inquiry.

\footnotetext{
${ }^{14}$ Based on IRS State Sales Tax Deduction tables, 2005 Instructions for Schedules A \& B (Form 1040).
} 


\section{References}

Brown, Jr., G. M., and H. O. Pollakowski (1977). "Economic Value of Shoreline," Review of Economics and Statistics, 59, 272-278.

Carlino, G. and N. E. Coulson (2004). "Compensating Differentials and the Social Benefits of the NFL," Journal of Urban Economics, 56, 25-50.

Carlino, G. and N. E. Coulson (2006). "Compensating Differentials and the Social Benefit of the NFL: Reply," Journal of Urban Economics, 60(1), 132-138.

Cassal, E., and R. Mendelsohn (1985). "The Choice of Functional Forms for Hedonic Price Equations: Comment," Journal of Urban Economics, 18, 135-142.

Coates, Dennis, B. R. Humphreys, and A. Zimbalist (2006). "Compensating Differentials and the Social Benefits of the NFL: A Comment," Journal of Urban Economics, 60(1), 124-131.

Colwell, P., C. Dehring, and N. Lash (2000). "The Effect of Group Homes on Neighborhood Property Values," Land Economics, 76(4), 615-636.

Correll, M., Lillydahl, J., and Singell, L (1978). "The Effect of Greenbelts on Residential Property Values: Some Findings on the Political Economy of Open Space," Land Economics, 54(2), 207-217.

Darling, A. (1973). "Measuring Benefits Generated by Urban Water Parks," Land Economics, 49(1), 22-34.

Dehring, C. A. and N. Dunse (forthcoming) "Housing Density and the Effect of Proximity to Public Open Space in Aberdeen, Scotland," Real Estate Economics.

Depken, C. A. (2006). "The Impact of New Stadiums on Professional Baseball Team Finances," Public Finance and Management, 6(3), 436-474.

Downes, T. A. and J. E. Zabel (2002). "The impact of school characteristics on house prices: Chicago 19871991," Journal of Urban Economics, 52(1), 1-25.

Epsey, M., and K. Owusu-Edusei (2001). "Neighborhood Parks and Residential Property Values in Greenville, South Carolina," Journal of Agricultural and Applied Economics, 33(3), 487-492.

Irwin, G. (2002). "The Effects of Open Space on Residential Property Values," Land Economics, $78(4), 465-480$.

Knetch, J. L. (1964). "The Influence of Reservoir Projects on Land Values," Journal of Farm Economics, 46, 231-243.

Lansford, Jr., N. H., and L. L. Jones. (1995). "Marginal Price of Lake Recreation and Aesthetics: An Hedonic Approach," Journal of Agricultural and Applied Economics, 27, 212-223.

Man, J. Y. and Bell, M. E. (1996). "The Impact of Local Sales Tax on the Value of OwnerOccupied Housing," Journal of Urban Economics, 39(1), 114-130. 
MacKinlay, A. (1997). "Event Studies in Economics and Finance," Journal of Economic Literature, 35, 3-39.

Rappaport, J. and C. Wilkerson (2001). "What are the Benefits of Hosting a Major League Sports Franchise?" Economic Review, Federal Reserve Bank of Kansas City, First Quarter, 55-86.

Rosen, S. (1973). "Hedonic Prices and Implicit Markets: Product Differentiation in Pure Competition," Journal of Political Economy, 82, 34-55.

Sirmans, G. Stacy, D. A. Macperson, and E. N. Zietz. (2005). "The Composition of Hedonic Pricing Models," Journal of Real Estate Literature, 13(1), 3-43.

Tu, C. (2005), "How Does a New Sports Stadium Affect Housing Values?" Land Economics, 81, 379-395.

Weicher, J. and Zerbst, R. 1973. "The Externalities of Neighborhood Parks: an Empirical Investigation," Land Economics, 49(1), 99-105.

Siegfried, J. and A. Zimbalist (2000). "The Economics of Sports Facilities and Their Communities," The Journal of Economic Perspectives, 14(3), 95-114. 
Table 1: Dallas Cowboys Stadium Announcements

\begin{tabular}{lll} 
& Date & Description \\
\hline Announcement 1 & April 30, 2004 & Proposal to build a stadium at Fair Park in downtown Dal- \\
& & las. The proposed stadium would replace the aging Cot- \\
& ton Bowl and the public contribution to construction costs \\
& would be financed by a half cent sales tax throughout Dallas \\
& County. Ultimately, the city of Dallas would not contribute \\
& to this additional tax because of contractual obligations to \\
& retire it's debt for the American Airlines Arena.
\end{tabular}

Announcement 2 June 9, 2004

Announcement 3 July 17, 2004

Announcement 4 August 17, 2004

Announcement 5 November 3, 2004
The Fair Park proposal officially abandoned

Arlington's mayor announces he has been in secret negotiations with the team about building a new publicly subsidized stadium near the existing baseball stadium in Arlington.

Arlington's city council approves a stadium ballot initiative for the November 2004 general election. The ballot initiative asks voters to approve up to $\$ 325$ million towards land acquisition and construction costs for a new stadium located near the existing baseball stadium in Arlington. The ballot initiative also includes a one half cent sales tax in Arlington as well as addditional hotel and car rental taxes.

Arlington voters approve ballot initiative on November 3, 2004, and the additional taxes are instituted on April 1, 2005. 
Table 2: Sample Descriptive Statistics

\begin{tabular}{|c|c|c|c|c|}
\hline \multirow[b]{2}{*}{ Variable } & \multicolumn{2}{|c|}{ Dallas Sample } & \multicolumn{2}{|c|}{ Arlington Sample } \\
\hline & Mean & Std. Dev. & Mean & Std. Dev \\
\hline Log of Price & 11.97 & 0.61 & 11.86 & 0.64 \\
\hline Age (years) & 23.26 & 17.15 & 22.64 & 18.56 \\
\hline Square Feet & 2165.00 & 911.09 & 2078.58 & 877.65 \\
\hline Pool $(1=$ Yes $)$ & 0.17 & 0.38 & 0.15 & 0.35 \\
\hline Number of Bathrooms & 2.52 & 0.92 & 2.42 & 0.88 \\
\hline Number of Garage Spots & 1.79 & 0.83 & 1.76 & 0.83 \\
\hline Number of Stories & 1.33 & 0.48 & 1.30 & 0.48 \\
\hline February & 0.09 & 0.29 & 0.08 & 0.27 \\
\hline March & 0.08 & 0.27 & 0.08 & 0.27 \\
\hline April & 0.08 & 0.28 & 0.09 & 0.28 \\
\hline May & 0.08 & 0.28 & 0.08 & 0.28 \\
\hline June & 0.09 & 0.29 & 0.09 & 0.29 \\
\hline July & 0.09 & 0.28 & 0.09 & 0.29 \\
\hline August & 0.08 & 0.28 & 0.09 & 0.28 \\
\hline September & 0.07 & 0.26 & 0.07 & 0.26 \\
\hline October & 0.07 & 0.25 & 0.07 & 0.26 \\
\hline November & 0.06 & 0.24 & 0.07 & 0.25 \\
\hline December & 0.07 & 0.25 & 0.07 & 0.26 \\
\hline Time Trend & 7.11 & 3.58 & 6.89 & 3.43 \\
\hline Dallas & 0.23 & 0.42 & & \\
\hline Dallas County & 0.46 & 0.49 & & \\
\hline Arlington & & & 0.13 & 0.33 \\
\hline Announcement 1 & 0.63 & 0.48 & & \\
\hline Announcement 2 & 0.52 & 0.49 & & \\
\hline Announcement 3 & & & 0.39 & 0.48 \\
\hline Announcement 4 & & & 0.30 & 0.46 \\
\hline Announcement 5 & & & 0.10 & 0.31 \\
\hline Dallas Announcement 1 & 0.17 & 0.37 & & \\
\hline Dallas Announcement 2 & 0.14 & 0.35 & & \\
\hline Arlington Announcement 3 & & & 0.06 & 0.23 \\
\hline Arlington Announcement 4 & & & 0.05 & 0.21 \\
\hline Arlington Announcement 5 & & & 0.02 & 0.13 \\
\hline Number of Observations & 42,351 & & 32,061 & \\
\hline Elementary Schools & 745 & & 689 & \\
\hline
\end{tabular}

Notes: Data reflect residential property sales from January 1, 2004 through February 28, 2005 with complete data and located within twenty miles of the Cotton Bowl for the Dallas sample and the Ballpark in Arlington for the Arlington sample. Data obtained from the Dallas-Fort Worth Metroplex Multiple Listing Service. January is used as the reference month. Dummy variable means do not sum to one because of rounding. 
Table 3: Estimated Values of Housing Characteristics

Dallas Sample

(1)
Arlington Sample

(2)

\begin{tabular}{lcc}
\hline Age & $-0.013^{* * *}(0.001)$ & $-0.013^{* * *}(0.001)$ \\
Age squared $\left(\times 10^{-3}\right)$ & $0.149^{* * *}(0.018)$ & $0.127^{* * *}(0.017)$ \\
Square Footage $\left(\times 10^{-3}\right)$ & $0.511^{* * *}(0.018)$ & $0.550^{* * *}(0.017)$ \\
Square Footage squared $\left(\times 10^{-6}\right)$ & $-0.029^{* * *}(0.002)$ & $-0.004^{* * *}(0.002)$ \\
Pool $(1=$ Yes $)$ & $0.081^{* * *}(0.004)$ & $0.087^{* * *}(0.004)$ \\
Bathrooms & $0.045^{* * *}(0.004)$ & $0.049^{* * *}(0.005)$ \\
Covered Parking Spots & $0.047^{* * *}(0.003)$ & $0.055^{* * *}(0.004)$ \\
Number of Stories & $-0.096^{* * *}(0.006)$ & $-0.098^{* * *}(0.006)$ \\
Constant & $11.10^{* * *}(0.029)$ & $10.96^{* * *}(0.028)$ \\
Observations & 42,351 & 32,061 \\
$R^{2}$ & 0.89 & 0.89 \\
\hline
\end{tabular}

Dependent variable is $\log$ of sale price. Specifications include monthly dummy variables and a monthly time trend. The Dallas sample is centered on Fair Park in downtown Dallas. The Arlington sample is centered on the Rangers baseball stadium in Arlington. The errors are clustered on elementary schools. Robust standard errors in reported in parentheses. ${ }^{* * *} p<0.01,{ }^{* *} p<0.05,{ }^{*} p<0.1$ 
Table 4: Unconstrained Stadium Announcement Effects

\begin{tabular}{rcc} 
& $\begin{array}{c}\text { Dallas Sample } \\
(1)\end{array}$ & $\begin{array}{c}\text { Arlington Sample } \\
(2)\end{array}$ \\
\hline Announcement 1 & $0.008(0.029)$ & \\
Announcement 2 & $0.006(0.010)$ & \\
Dallas City & $-0.008(0.029)$ & \\
Dallas City $\times$ Announcement 1 & $0.021^{* *}(0.011)$ & \\
Dallas City $\times$ Announcement 2 & $-0.005(0.011)$ & \\
Dallas County & $0.012(0.021)$ & \\
Dallas County $\times$ Announcement 1 & $-0.008(0.007)$ & \\
Dallas County $\times$ Announcement 2 & $0.008(0.006)$ & \\
Arlington & & $-0.010(0.037)$ \\
Announcement 3 & & $0.004(0.008)$ \\
Announcement 4 & & $-0.004(0.009)$ \\
Announcement 5 & & $0.009(0.017)$ \\
Arlington $\times$ Announcement 3 & & $-0.002(0.011)$ \\
Arlington $\times$ Announcement 4 & & $-0.011(0.012)$ \\
Arlington $\times$ Announcement 5 & & $0.001(0.009)$ \\
\hline
\end{tabular}

Dependent variable is log of sale price. All specifications include house age, age squared, square footage, square footage squared, number of bathrooms, number of garage parking spots, whether the property has a pool or not, the number of stories, month-specific dummy variables, a time trend, and elementary-school fixed effects. The Dallas sample is centered on Fair Park in downtown Dallas. The Arlington sample is centered on the Rangers baseball stadium in Arlington. The errors are clustered on elementary-schools. Robust standard errors in reported in parentheses. ${ }^{* * *} p<0.01,{ }^{* *} p<0.05,{ }^{*} p<0.1$ 
Table 5: Constrained Stadium Announcement Effects

\begin{tabular}{rcc} 
& Dallas Sample & $\begin{array}{c}\text { Arlington Sample } \\
(2)\end{array}$ \\
\hline Accumulated General Announcement Effects & $-0.007(0.009)$ & $0.001(0.005)$ \\
Dallas City & $0.003(0.029)$ & \\
Dallas County & $0.007(0.021)$ & \\
Dallas City $\times$ Accumulated Announcement Effects & $0.012(0.010)$ & \\
Dallas County $\times$ Accumulated Announcement Effects & $0.004(0.003)$ & \\
Arlington & & $-0.011(0.037)$ \\
Arlington $\times$ Accumulated Announcement Effects & & $-0.005^{* *}(0.002)$ \\
\hline
\end{tabular}

Dependent variable is log of sale price. All specifications include house age, age squared, square footage, square footage squared, number of bathrooms, number of garage parking spots, whether the property has a pool or not, the number of stories, month-specific dummy variables, a time trend, and elementary-school fixed effects. The Dallas sample is centered on Fair Park in downtown Dallas. The Arlington sample is centered on the Rangers baseball stadium in Arlington. The errors are clustered on elementary schools. Robust standard errors in reported in parentheses. ${ }^{* * *} p<0.01,{ }^{* *} p<0.05,{ }^{*} p<0.1$ 